\title{
Nephro- and hepatoprotective effect of Rosmarinus officinalis against damage induced with antiTB drugs using a chronic model
}

\author{
Siordia-Reyes Georgina A ${ }^{1}$, Cornejo-Garrido Jorge ${ }^{2}$, Jiménez-Arellanes M. Adelina ${ }^{3, *}$
}

\section{Siordia-Reyes Georgina A', Cornejo-Garrido Jorge ${ }^{2}$, Jiménez- Arellanes M. Adelina ${ }^{3, *}$}

'Departamento de Patología, UMAE Hospital de Pediatría, Centro Médico Nacional Siglo XXI (CMN-SXXI), Instituto Mexicano del Seguro Social (IMSS), Av. Cuauhtémoc 330, Col. Doctores, 06720, Ciudad de México (CDMX), MEXICO.

${ }^{2}$ Laboratorio de Biología Celular y Productos Naturales, Escuela Nacional de Medicina y Homeopatía (ENMH), Instituto Politécnico Nacional, Guillermo Massieu Helguera 239, Col. La Escalera, Del. Gustavo A. Madero, 07320 CDMX, MEXICO.

${ }^{3}$ Unidad de Investigación Médica (UIM) en Farmacología, UMAE Hospital de Especialidades, CORSE $2^{\circ}$ piso, CMN-SXXI, IMSS, Av. Cuauhtémoc 330, Col. Doctores, 06729, CDMX, MEXICO.

\section{Correspondence}

\section{M.A. Jiménez-Arellanes}

UIM en Farmacología, Hospital de

Especialidades, CMN Siglo XXI, IMSS Av.

Cuauhtémoc 330, Col. Doctores, 06720

Ciudad de México, MEXICO.

Phone no: (+52) (55) 5627 6900, ext. 21367;

E-mail: adelinajim08@prodigy.net.mx History

- Submission Date: 02-03-2021;

- Review completed: 29-03-2021;

- Accepted Date: 09-04-2021.

DOI : 10.5530/pj.2021.13.92

Article Available online http://www.phcogj.com/v13/i3

\section{Copyright}

(C) 2021 Phcogi.Com. This is an openaccess article distributed under the terms of the Creative Commons Attribution 4.0 International license.

\section{ABSTRACT}

Nephro- and hepatoprotector effect of $\mathrm{MeOH}$ extract from $R$. officinalis against the liver and kidney damage caused by the mixture of RIF:INH:PZA, using a chronic in vivo model are described. $\mathrm{MeOH}$ extract (EMRO) was prepared by maceration process and was administered by oral via during 91 days in male Balb/C mice with RIF:INH:PZA-induced renal/liver damage, using silymarin (SIL) as a positive control. EMRO $(250 \mathrm{mg} / \mathrm{kg})$ favoured body weight gain respect to the antiTB group, this gain was better than that shown by the SIL. The AST and ALT values of the group that received the EMRO extract and SIL were similar to that the control group and low compared to the group antiTB with liver damage. In addition, the GPX, CAT and POx values of the group treated with the EMRO were similar to that the control group. In the liver histological analysis, no significant alteration was observed; however, a severe nephritis was observed in anti-TB group (II) and this effect was less in groups III (antiTB/SIL) and IV (antiTB/EMRO). MeOH extract enhances body weight gain and primarily protects the kidney and liver from damage caused by the antiTB drug mixture when was administered for 91 days Key words: Methanolic extract, Antitubercular drug, Rosmarinus officinalis, Hepatoprotection, Nephroprotective effect.

\section{INTRODUCTION}

Rosmarinus officinalis (Lamiaceae family) is common know as Rosemary; it has global distribution and, it is widely used as a condiment, ornamental, and as a medicinal species..$^{1-3}$ Is used to treat discomfort of the digestive apparatus (stomachache, diarrhea, gastritis, intestinal parasites, colitis), and favors hepatic function and stimulates the bile production. Also, is used as analgesic against menstrual colic, treats vaginal infections, respiratory disorders, varicose veins, cardiovascular problems, healing, dizziness, headaches, cancer, type 2 diabetes mellitus (T2DM), and reduces obesity. ${ }^{1,2,4-7}$

R. officinalis is an important source of antioxidant, anti-inflammatory, antinociceptive, antiulcerogenic, neuro- and hepatoprotector, hypolipidemic, antiviral, anticancer and antimicrobial compounds. It mainly biosynthesizes triterpenes and phenolic compounds such as: rosmarynic acid, betulinic acid, micromeric acid, oleanolic acid (OA), ursolic acid (UA), apigenine, diomine, luteolin, carnosic acid, carnosol, chlorogenic acid, caffeic acid, $\alpha-y$ $\beta$-pinene, campfor, rosmadial, rosmanol, among others. UA and carnosol obtained from methanolic $(\mathrm{MeOH})$ extract have antimicrobial, anticancer, antinocciceptive, and tripanocide properties. ${ }^{2,3,5,8-13}$

Regarding the hepatoprotector (HPP) effect of $R$. officinalis, it has been reported that the aqueous $\left(\mathrm{H}_{2} \mathrm{O}\right), \mathrm{MeOH}$, or ethanolic $(\mathrm{EtOH})$ extracts from $R$. officinalis showed a HPP effect against liver damage induced with streptozotocine (STZ), azathioprine, coal tar creosote, $\mathrm{CCl}_{4}$; lead acetate $\left[\mathrm{Pb}\left(\mathrm{C}_{2} \mathrm{H}_{3} \mathrm{O}_{2}\right)_{2}\right] \cdot{ }^{14,15-18}$ In addition, the $\mathrm{MeOH}$ extract of $R$. officinalis $(200 \mathrm{mg} / \mathrm{kg})$ and carnosol $(5 \mathrm{mg} / \mathrm{kg})$ protect the liver, and partially normalize biochemical markers against the acute damage induced with $\mathrm{CCl}_{4}(4 \mathrm{~g} / \mathrm{kg}$, single doses) on male Sprague Dawley rats, through its antioxidant effect and free radical scavenger effect. The authors conclude that the HPP effect of the extract is due to its carnosol content. ${ }^{16,17}$

In rabbits with hepato-renal damage induced with $\mathrm{Pb}\left(\mathrm{C}_{2} \mathrm{H}_{3} \mathrm{O}_{2}\right)_{2}$ and treated with EtOH $(80 \%)$ extract at $30 \mathrm{mg} / \mathrm{kg}$ administered during 30 days by intragastric via (i.g.) route. This extract favored the body weight gain (BWG). In addition, the Lpx, ALT, AST and ALP values in the group co-administered with the EtOH extract were reduced and the levels of SOD and CAT were slightly higher (without reaching the control group levels). $\mathrm{Pb}\left(\mathrm{C}_{2} \mathrm{H}_{3} \mathrm{O}_{2}\right)_{2}$ group showed degeneration of hepatocytes, hyperplasia, severe congestion of hepatic vessels, and in the group treated with $\mathrm{EtOH}$ extract, the structure of hepatocytes showed restoration. In conclusion, the administration of this extract is a good HPP against the damage caused by $\mathrm{Pb}\left(\mathrm{C}_{2} \mathrm{H}_{3} \mathrm{O}_{2}\right)_{2}$ by antioxidant properties. ${ }^{18}$ However, the HPP effect of $R$. officinalis against chronic damage caused by anti-TB drugs has not been reported.

On the other hand, tuberculosis (TB) is a global health problem (one of the top 10 causes of death); it causes approximately 1.3 million deaths/year, and every year 11 million develop the disease, of whom between 10 and $12 \%$ are HIV-positive, this co-infection being the main cause of mortality. Currently, the multidrugresistant TB (TB-MDR) and of extensively drugresistant TB (TB-XDR) are increasing. Around $60 \%$ of MDR cases respond to treatment, and approximately $10 \%$ become TB-XPR. Rifampicin

Cite this article: Siordia-Reyes GA, Cornejo-Garrido J, Jiménez-Arellanes MA. Nephro- and hepatoprotective effect of Rosmarinus officinalis against damage induced with antiTB drugs using a chronic model. Pharmacog J. 2021;13(3): 722-9 
(RIF), isonizide (INH) and pirazinamide (PZA) are basic drugs to TB treatment and cannot be replace. These mainly cause hepatotoxicity (HPT), as well as neuropathy, hypersensitivity, nephrotoxicity, nausea, vomiting, and gastritis. The HPT incidence depends on the study population, duration of treatment, age, malnutrition, alcoholism, T2DM, arthritis, HIV/AIDS, cancer and other. Bio-transformation of antiTB drugs is performed in the liver, making it the most affected when metabolizing these drugs, which promote very reactive products, which alter its integrity and function, generating inflammation, chronic hepatitis, hepatic fibrosis, non-alcoholic cirrhosis, and even hepatocellular carcinoma, these being the main reasons for withdrawing drugs from the market. ${ }^{19-22}$ Nephrotoxic drugs are those that cause an adverse effect and compromise the kidneys' function; although antiTB drugs have been described as nephrotoxic, this effect has been little studied and, even worse, the nephroprotector effects of extracts or natural-origin compounds has not been explored before the damage caused by antiTB drugs. ${ }^{23}$ In this sense, it has been reported that Ruta graveolens has a hepatoprotector, and nephroprotector effect against the damage caused by diethylnitrosamine (DEN) in rats. ${ }^{24}$ Recently, EtOH (80\%) extract from R. graveolens leaves (50 and $100 \mathrm{mg} / \mathrm{kg}$ ) showed a nephroprotector effect in male Wistar rats with renal damage caused by the INH:RIF (50:50 $\mathrm{mg} / \mathrm{kg}$ ) mixture. The extract and antiTB drugs were administered by oral via over 45 days. In this study, the extract at both doses reduced the urea, creatinine and uric acid levels, as well as TNF- $\alpha$ and Lpx values respect to INH:RIF group. Also, the extract at both doses reduced atrophy of the glomerular tube and the infiltration of inflammatory cells that is generated by the mixture of INH:RIF; in addition, it increased levels of GPx, SOD and GSH..$^{23}$

To the best of our knowledge, there is no report on the nephro- and hepatoprotector effect of the $\mathrm{MeOH}$ extract from $R$. officinalis against damage caused by the RIF:INH:PZA mixture, using a chronic in vivo model. This paper describes the results on these effect determined in Balb/C mice with damage induced with RIF:INH:PZA mixture administered by oral via during 91 days.

\section{MATERIAL AND METHODS}

\section{Plant material and preparation of the extract}

R. officinalis (aerial parts) was collected in Oaxaca, Mexico in April, 2014, was identified by MSc Abigail Aguilar from the Herbarium, IMSS, Mexico (IMSSM), and a sample was deposited in this herbarium

$\mathrm{MeOH}$ extract was obtained by maceration at room temperature and the solvent was removed by means of vacuum, this process allowed to obtain the extract free of organic solvent (EMRO), which was maintained in refrigeration and darkness until use.

\section{In vivo assay}

Male Balb/C mice were used ( $24 \pm 2 \mathrm{~g}$ ), from the IMSS vivarium, and were kept under standard laboratory conditions according to the Norma Oficial Mexicana (NOM-062-ZOO-1999) as modified in 2016. ${ }^{25}$ The animals received care according to the Guide for the Care and Use of Laboratory Animals of the National Academy of Science. The protocol was approved by the Local Scientific Research Commission, IMSS (CLIC R-2015-3601-47). Food and water were provided ad libitum.

Nephro- and hepatoprotector effect of the R. officinalis extract (EMRO) in an in vivo model

The assay was carried out following the methodology previously described, ${ }^{26,27}$ with some modifications. Damage was induced with the mixture of antiTB drugs (RIF:INH:PZA, 10:10:30 mg/ $\mathrm{kg}$, each) solubilized in carboxymethylcellulose (CMC) at $0.5 \%$ in SSI and administered by i.g. route, in a volume no greater than 10 $\mathrm{mL} / \mathrm{kg}$. The EMRO extract and silymarin (SIL, positive control for hepatoprotection) were solubilized in the vehicle [Tween 80:CMC (0.5:9.5)] and were administered by i.g. route daily for 91 days, 2 hours after the administration of the antiTB mixture. 4 groups were formed ( $\mathrm{n}$ $=8$ ), which received the following treatment: Group I: Vehicle, Group II: antiTB, Group III: antiTB/SIL $(2.5 \mathrm{mg} / \mathrm{kg})$ and Group IV: antiTB/ $\operatorname{EMRO}(250 \mathrm{mg} / \mathrm{kg})$.

During the period of the experiment (91 days), the BWG was recorded every third day. Upon ending the experiment, blood was taken without anticoagulant (by retro-orbital puncture) with previous fast of 12 hours. After, the animals were sacrifice by dislocation and the liver and kidney extracted to be weighed and for histological analysis.

Levels of ALT, AST and ALP were determined in serum and was analyze in automated Selectra II Analyser (Modelo Vitalab 2) equipment, using the commercial kit Brand (Randox LAB). Catalase activity (CAT) and oxidated glutation (GPx) were determined in the supernatant of the liver homogenate by colormetric method. Levels of oxidated proteins (POx) and oxidated lipids (Lpx) were determined according to that previously described. ${ }^{26,27}$

\section{Histological analysis}

This trial was performed in accordance with that previously described. ${ }^{26,27}$.

\section{Statistical analysis}

The program SigmaPlot ver. 12.5 was use for analysis of results and graphics. Data are presented as standard error mean (SEM). Body weight gain (BWG) was analyzed by ANOVA and with the StudentNewman-Keuls (SNK) post-hoc test. Results with $p<0.05$ were considered statistically significant. Biochemical and oxidative stress parameters were analyzed with one-way ANOVA and SNK post-hoc test.

\section{RESULTS}

\section{Extract obtention}

$10.6 \mathrm{~g}$ of EMRO extract was obtained from $450 \mathrm{~g}$ of dry plant material, with a yield of $2.35 \%$. Previously, has been reported that $\mathrm{CHCl}_{3}, \mathrm{MeOH}$, $\mathrm{EtOH}$ or aqueous extracts from $R$. officinalis (leaves) contain rosmarinic acid, betulinic acid, micromeric acid, OA, UA, apigenin, diosmin, luteolin, carnosic acid, rosmainic acid, carnosol, chlorogenic acid, caffeic acid, $\alpha$ - y $\beta$-pinene, campfor, rosmadial, rosmanol, among others. These compounds are responsible for the several biological activities (anti-inflammatory, antinociceptive, hepatoprotector, antioxidant and antimicrobial, among others) described for the species. ${ }^{1,2,5,28-30}$ In EMRO extract rosmarinic acid, carnosol and the UA/OA mixture we detected using TLC and reference standard.

\section{Nephro- and hepatoprotector effect of the EMRO extract against the damage induced by the RIF:INH:PZA mixture during 91 days}

The nephroprotector and HPP effects of the MeOH extract (EMRO, at a dose of $250 \mathrm{mg} / \mathrm{kg})$ and SIL $(2.5 \mathrm{mg} / \mathrm{kg}$, positive control for hepatoprotection), administered over 91 days by i.g. route was determined in Blab/C mice. In Table 1 shows the values of BWG. Group I (vehicle) showed a constant BWG during period of the study; at day 91 the final BWG was $2.21 \mathrm{~g}$. Group II (antiTB) showed lower BWG compared with the control (Group I), and from day 56 to day 70 weight loss was very evident, showing poor gain, being 0.25 and $0.83 \mathrm{~g}$, respectively. From day $84(1.41 \mathrm{~g})$ to $91(1.75 \mathrm{~g})$, a slight increase was seen in this parameter; however, at the end of treatment, the BWG was lower than group I ( $1.75 \mathrm{~g}$ vs $2.21 \mathrm{~g}$ ). BWG in Group III (antiTB/SIL) was constant, but lower respect to group II (antiTB) and group I (control); at the end of the study the BWG was $1.16 \mathrm{~g}$. Group IV (antiTB/EMRO) showed a constant BWG, it was slightly lower than group I (control), this 
weight gain was better than that observed for II and III groups. At days 70,84 and 91 , BWG was $1.58,1.94$ and $2.11 \mathrm{~g}$, respectively. It should be noted that the EMRO favored BWG with respect to the positive control (SIL) during the period of the experiment. Upon analyzing the weight of liver, spleen and kidney, no significant differences were observed in the weight of these organs (Table 2).

The results regarding levels of hepatic enzymes (ALP, AST and ALT) are show in Table 3. The level of AST increased $50 \%$ in group II (antiTB), showing a level of 346.50 UI compared with group I (control, 231.00 UI); to the contrary, III and IV groups [antiTB/SIL (247.43 UI) and antiTB/EMRO (247.14 UI)] showed levels very similar to the control (group I, 231.00 UI) and were lower than group II (with antiTB). Levels of ALT showed an increase of $91.58,63.16$ and $63.67 \%$ in II, III and IV groups (antiTB, antiTB/SIL and antiTB/EMRO, respectively) compared with group I (vehicle). The increase was greater in group II (antiTB) compared with group I (280.70 vs 146.15 UI) and groups III and IV, which received SIL and EMRO, showed levels of 238.46 and $249.23 \mathrm{UI}$, respectively. In the case of ALP level, the groups II (antiTB), III (antiTB/ SIL) and IV (antiTB/EMRO) showed levels similar to the control group (198.77, 190.31 and 192.30 UI vs 184.61 UI).

In Table 3, the GPx, CAT, POx and Lpx values are showed, this was quantified in liver. Analysis of the results showed that GPx value were slightly higher in groups I, III and IV (control, antiTB/SIL and antiTB/ EMRO) respect to group II (antiTB), the values was 788.23, 783.06 and $801.02 \mathrm{mM}$ vs $742.13 \mathrm{mM}$, respectively. It is worth noting that group IV (antiTB/EMRO) showed levels similar to the control (group I) and SIL group (III); however, these differences were not statistically significant. CAT levels for group II (antiTB) was $326.29 \mu \mathrm{M}$ and for the control showed $237.45 \mu \mathrm{M}$. Group IV (antiTB/EMRO) showed a high level respect to control -group I- (383.90 vs $237.45 \mu \mathrm{M})$, this level was higher than groups II (antiTB) and III (antiTB/SIL), with values of 326.29 and $332.72 \mu \mathrm{M}$, respectively. In regards to levels of POx, the following

Table 1: Body weight gain (BWG) of male Balb/C mice with kidney and liver damage caused with RIF:INH:PZA and treated with the MeOH extract of $R$. officinalis (EMRO) for 91 days.

\begin{tabular}{ccccc}
\hline & \multicolumn{3}{c}{ BWG (g) } \\
\hline Day & Group I & Group II & Group III & Group IV \\
\hline 0 & 0 & 0 & 0 & 0 \\
14 & $0.21 \pm 0.11$ & 0 & 0 & $0.22 \pm 0.10$ \\
28 & $1.21 \pm 0.31$ & $0.75 \pm 0.24$ & $0.25 \pm 0.17$ & $0.88 \pm 0.20$ \\
42 & $1.78 \pm 0.38$ & $1.00 \pm 0.26$ & $0.41 \pm 0.18$ & $1.27 \pm 0.21$ \\
56 & $1.21 \pm 0.38$ & $0.25 \pm 0.12$ & $0.33 \pm 0.24$ & $1.35 \pm 0.24$ \\
70 & $1.57 \pm 0.38$ & $0.83 \pm 0.23$ & $0.66 \pm 0.27$ & $1.58 \pm 0.23$ \\
84 & $1.64 \pm 0.35$ & $1.41 \pm 0.32$ & $0.66 \pm 0.18$ & $1.94 \pm 0.32$ \\
91 & $2.21 \pm 0.48$ & $1.75 \pm 0.37$ & $1.16 \pm 0.33$ & $2.11 \pm 0.35$
\end{tabular}

Data presented as mean $( \pm)$ with standard error of the mean (SEM).

Bifactorial Repeated Measures (MR) statistical analysis (ANOVA), post hoc Student Newman Keuls (SNK) test (p $<0.05), \mathrm{n}=10$.

Group I: vehicle (Tween 80:CMC 0.5\%, 0.5:9.5); Group II: antiTB (RIF:INH:PZA, 10:10:30 mg/kg); Group III: antiTB/ SIL, $2.5 \mathrm{mg} / \mathrm{kg}$ ) and Group IV: antiTB/EMRO (MeOH extract of the R. officinalis $250 \mathrm{mg} / \mathrm{kg})$.

Table 2: Organ weights of male Balb/C mice with kidney and liver damage caused by RIF:INH:PZA and treated with the MeOH extract of R. officinalis (EMRO) for 91 days.

\begin{tabular}{|c|c|c|c|c|}
\hline \multirow{2}{*}{ organ } & \multicolumn{4}{|c|}{ Treatment } \\
\hline & Group I & Group II & Group III & Group IV \\
\hline liver $(\mathrm{g})(\%)$ & $1.42 \pm 0.04(4.81 \pm 0.11)$ & $1.23 \pm 0.04(4.38 \pm 0.12)$ & $1.22 \pm 0.03(4.31 \pm 0.13)$ & $1.45 \pm 0.05(5.00 \pm 0.13)$ \\
\hline spleen $(\mathrm{g})(\%)$ & $0.16 \pm 0.04(0.53 \pm 0.13)$ & $0.14 \pm 0.03(0.50 \pm 0.11)$ & $0.12 \pm 0.01(0.44 \pm 0.04)$ & $0.14 \pm 0.01(0.48 \pm 0.03)$ \\
\hline Kidney (g) (\%) & $0.45 \pm 0.02(1.51 \pm 0.05)$ & $0.36 \pm 0.03(1.29 \pm 0.12)$ & $0.42 \pm 0.02(1.49 \pm 0.06)$ & $0.46 \pm 0.01(1.59 \pm 0.04)$ \\
\hline
\end{tabular}

Data presented as mean $( \pm)$ with standard error of the mean (SEM). Holm-Sidak post hoc test, $\mathrm{n}=10$.

Group I: vehicle (Tween 80: CMC 0.5\%, 0.5:9.5); Group II: antiTB (RIF:INH:PZA, 10:10:30 mg/kg); Group III: antiTB/SIL (2.5 mg/kg); Group IV: antiTB/ EMRO (MeOH extract of the R. officinalis, $250 \mathrm{mg} / \mathrm{kg}$ ).

Table 3: Values of biochemical parameters of male Balb/C mice with kidney and liver damage caused with RIF:INH:PZA and treated with the MeOH extract of $R$. officinalis (EMRO) during 91 days.

\begin{tabular}{ccccc}
\hline Parameters & Group I & Group II & Group III & Group IV \\
\hline AST $(\mathrm{UI})$ & $231.00 \pm 11.39$ & $346.50 \pm 12.75$ & $247.43 \pm 12.62$ & $247.14 \pm 11.00$ \\
ALT $(\mathrm{UI})$ & $146.15 \pm 11.02$ & $280.70 \pm 13.03$ & $238.46 \pm 12.19$ & $239.23 \pm 11.65$ \\
ALP $(\mathrm{UI})$ & $184.61 \pm 9.78$ & $198.77 \pm 10.05$ & $190.31 \pm 11.04$ & $192.30 \pm 10.67$ \\
GPx $(\mathrm{mM})$ & $788.23 \pm 19.51$ & $742.13 \pm 18.14$ & $783.06 \pm 19.91$ & $801.02 \pm 17.11$ \\
CAT $(\mu \mathrm{M})$ & $237.45 \pm 12.75$ & $326.29 \pm 13.39$ & $332.72 \pm 12.99$ & $383.90 \pm 11.10$ \\
POx $(\mathrm{mM})$ & $7255.53 \pm 109.50$ & $9129.58 \pm 106.3$ & $7736.04 \pm 107.4$ & $7299.15 \pm 102.3$ \\
Lpx $(\mathrm{nM})$ & $49.87 \pm 9.20$ & $58.48 \pm 7.31$ & $47.49 \pm 10.27$ & $48.81 \pm 8.42$ \\
Creatinine $(\mathrm{mg} / \mathrm{dL})$ & $0.53 \pm 0.02$ & $0.84 \pm 0.01$ & $0.49 \pm 0.03$ & $0.57 \pm 0.04$ \\
Urea $(\mathrm{mg} / \mathrm{dL})$ & $75.27 \pm 0.88$ & $91.1 \pm 1.11$ & $71.77 \pm 0.28$ & $77.28 \pm 1.07$
\end{tabular}

Data presented as mean $( \pm)$ with standard error of the mean (SEM). Holm-Sidak post hoc test, $\mathrm{n}=10$. Group I: vehicle (Tween 80: CMC 0.5\%, 0.5:95); Group II: antiTB (RIF:INH:PZA, 10:10:30 mg/kg); Group III: antiTB/SIL (2.5 mg/kg); Group IV: antiTB/EMRO (MeOH extract of the R. officinalis, $250 \mathrm{mg} / \mathrm{kg}), \mathrm{n}=10$. 
behavior was observe antiTB $>$ antiTB/SIL $>$ antiTB/EMRO $>$ vehicle. Finally, levels of Lpx did not show significant differences, with levels between 47.49-50.48 $\mathrm{nM}$.

Respect to creatinine and urea values, these were elevated in Group II (antiTB) respect to the control (group I) see Table 3; however, these values were reduced in the group that received the EMRO extract (Group IV) and in SIL group (III).

The results of histological analysis from the liver are shown in Figures 1A-1D. According to the observations, none of the groups showed significant changes in hepatic parenchyma, nor was there evidence of steatosis, necrosis or inflammatory infiltrate. $25 \%$ of the animals of the group II (antiTB) showed scant lymphoid aggregate without the presence of germinal centers (interstitial nephritis). In the case of group III (antiTB/SIL), $80 \%$ of the animals (8/10) showed lymphoid aggregates with higher frequency and number of lymphoid cells in the interstice, with a tendency towards perivascular locations. In addition, $50 \%$ of the animals of the group IV (antiTB/EMRO) showed scant lymphoid infiltrate (isolated lymphoids). Finally, in Figure 2 (A-D) shown the microphotographs of the kidneys. The glomerulus and tubules in the all groups did not show important histological changes: Group II (antiTB) showed severe inflammatory lymphoid infiltrate that displaced the tubules and group III (antiTB/SIL) showed renal parenchyma with interstitial lymphoid infiltrate with perivascular disposition, meanwhile group IV (antiTB/EMRO) showed scant inflammatory interstitial lymphoid infiltrate. It is important mention that no animal died during the 91 days of the experiment.

\section{DISCUSSION}

The liver is the key organ where biotransformation of various substances takes place, among them, antiTB drugs; therefore, the disorders associated with this organ are numerous and varied. The antiTB drugs, upon metabolizing, generate more toxic compounds, altering the functional and structural integrity of this organ, while also generating inflammation, drug-related hepatitis (acute and/or chronic), hepatic fibrosis, steatosis and/or non-alcoholic cirrhosis, and on occasion even hepatocellular carcinoma. Three of the basic drugs for the treatment of TB are RIF, INH and PZA, which cause greater damage to the liver by increasing levels of AST, ALT and ALP; favoring the development of oxidative stress, lipoperoxidation and choline deficiency, thus altering the synthesis of phospholipoproteins. It should be noted that of these three drugs, PZA is the most hepatotoxic. ${ }^{31-33}$

At present, natural substances or extracts from medicinal plants with nephro- and/or hepatoprotective effect are wanted. In this regard, SIL was use as positive control because show a hepatoprotector effect in vivo and in vitro against the hepatic damage caused by antiTB drugs, in addition to having an antitubercular and antimycobacterial effect. ${ }^{32,34,35}$

The results showed that the EMRO extract (group IV) administered during 91 days by i.g. route favored BWG over group II (antiTB), this weight gain was better at the end of the experiment ( $2.11 \mathrm{~g}$ vs $1.75 \mathrm{~g}$ ). In addition, the BWG in the group that received the extract was higher than that shown by group III (antiTB/SIL, $1.16 \mathrm{~g}$ ), where silymarin was used as hepatoprotector. BWG during the period of experimentation

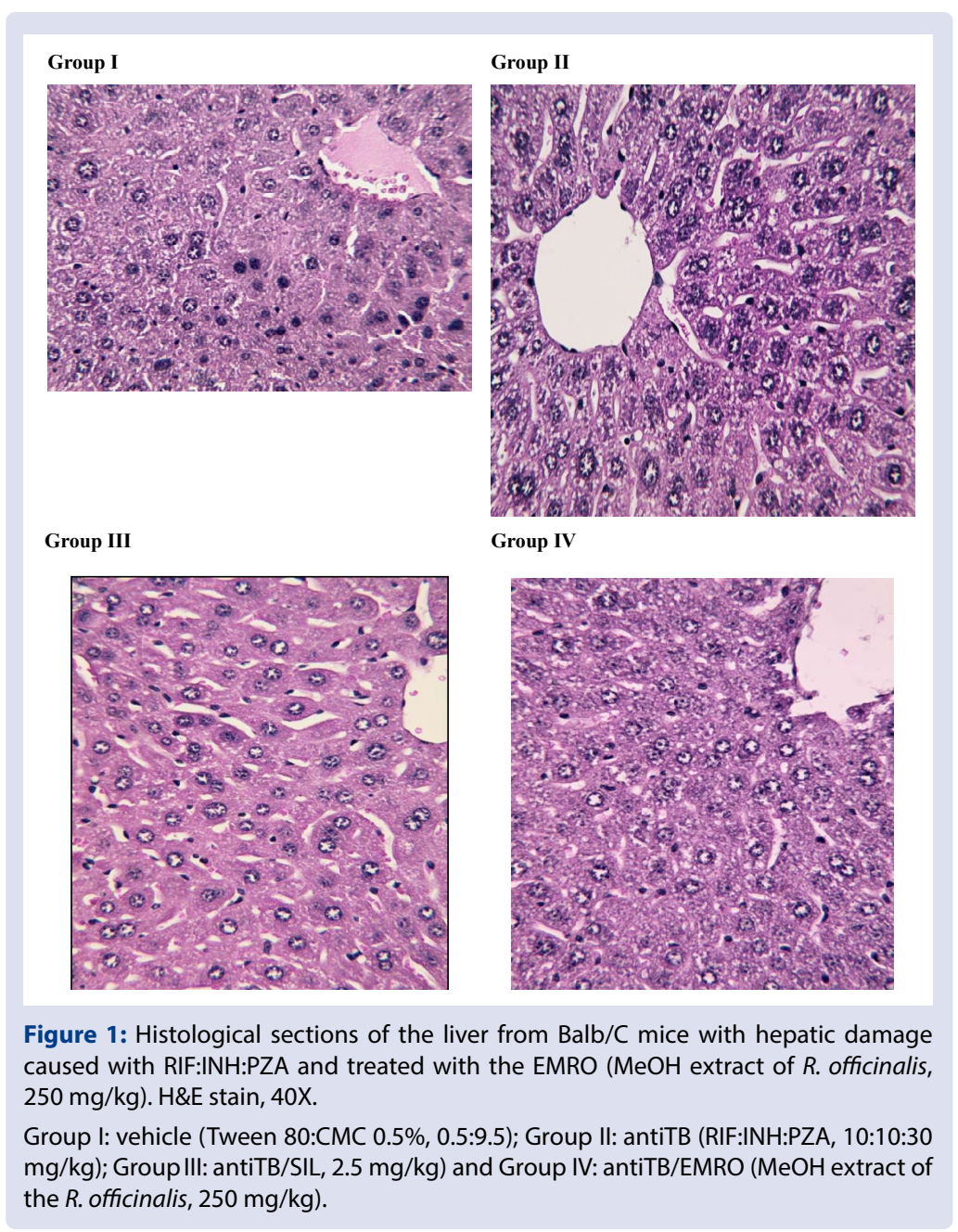




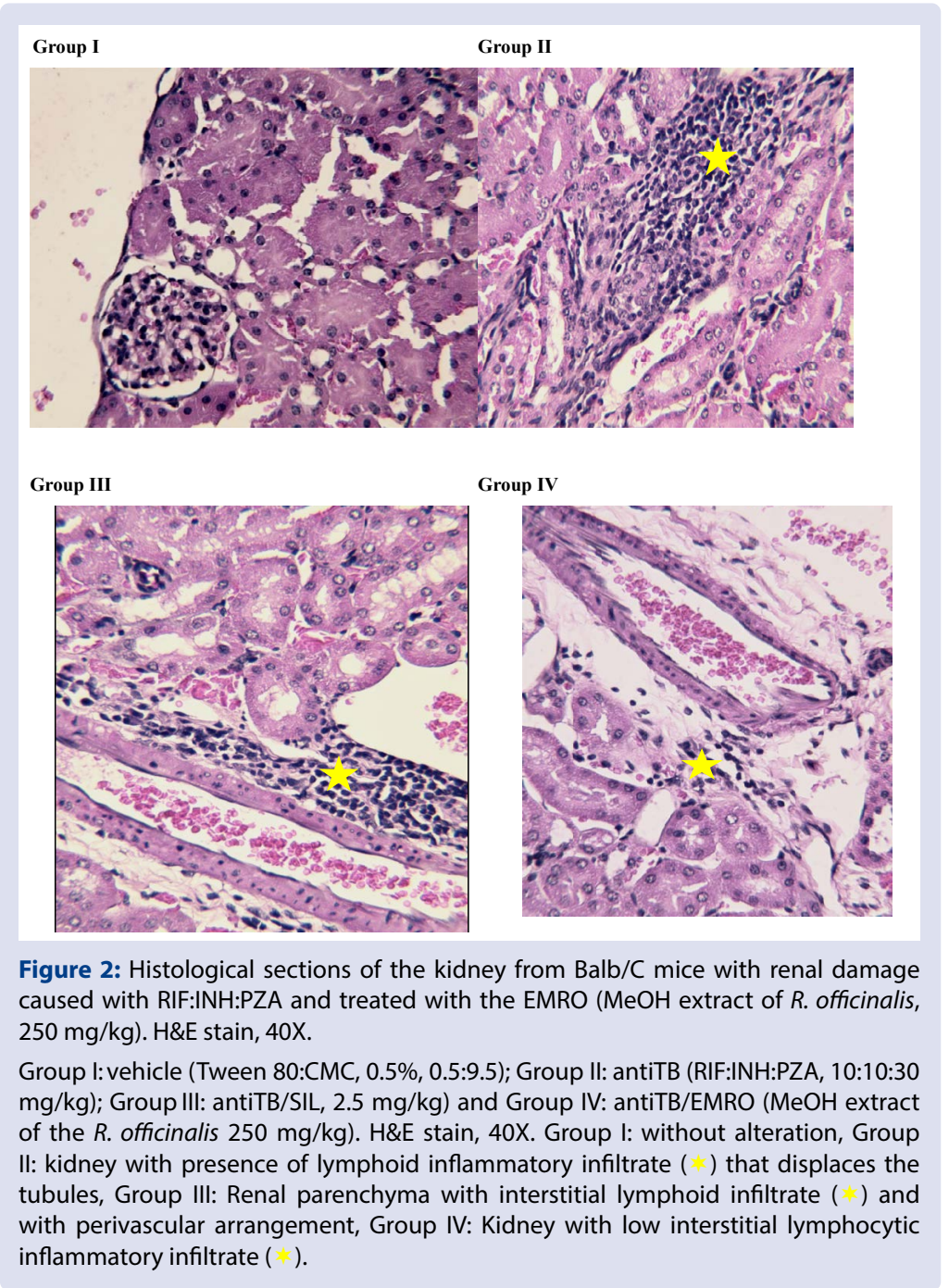

(91 days) in the group that received EMRO $(2.11 \mathrm{~g})$ was slightly less than control (BWG $=2.21 \mathrm{~g}$ ). It is important to mention that to date the effect of $R$. officinalis extract on BWG in mice or rats with liver damage has not been described. Only that of EtOH extract $(30 \mathrm{mg} /$ $\mathrm{kg}$ ) administered by i.g. route over 30 days favored BWG in rabbits with hepato-renal damage induced with $\mathrm{Pb}\left(\mathrm{C}_{2} \mathrm{H}_{3} \mathrm{O}_{2}\right)_{2}$ at $30 \mathrm{mg} / \mathrm{kg} \cdot{ }^{18} \mathrm{In}$ addition, in the present study, the organs weight was not altered.

In this study, it was observed that the levels of liver enzymes (AST and ALT) increased in group II (treated with anti-TB), this effect is due to the fact that the RIF:INH:PZA mixture generates severe liver damage. ${ }^{23,26}$ Instead, the animals that received antiTB/EMRO (group IV) showed low levels of AST and ALT respect to antiTB group (animals with hepatic damage, group II), but without reaching the levels of the control (group I). In this case, it was noted that the extract showed a protector effect against the damage caused by the antiTB (RIF:INH:PZA), effect similar to that shown by the positive control (SIL, Group III). Furthermore, the GPx and CAT levels were lower in antiTB group (group II) and these values increased in the group that received the EMRO extract, the increase was even higher than that observed for group III (antiTB/ SIL). Previously, it was reported that the $\mathrm{MeOH}$ extract of $R$. officinalis (with a carnosol content of $6.04 \mathrm{mg} / \mathrm{kg}$ of dry extract) at dose $200 \mathrm{mg} /$ $\mathrm{kg}$ and carnosol (main compound present in this extract) at dose 5 $\mathrm{mg} / \mathrm{kg}$ showed HPP effect against acute damage caused by $\mathrm{CCl}_{4}(4 \mathrm{~g} /$ $\mathrm{kg}$ ) in male Sprague Dawley rats. The authors found that this extract reduced the levels of AST and bilirubin; likewise, they observed that at a histological level the inflammation, necrosis and vacuolation generated by $\mathrm{CCl}_{4}$ (with a single administration) in the liver decreased. In addition, the authors reported that carnosol $(5 \mathrm{mg} / \mathrm{kg})$ also showed HPP effect due to its antioxidant activity (as free radical scavenger), since it, normalized plasma levels of bilirubin, reduced the content of Lpx and reduced by $50 \%$ levels of ALT. They concluded that the HPP activity of this extract was due mainly to the content of antioxidant compounds such as carnosol. ${ }^{16,17}$

It has also been reported that the $\mathrm{MeOH}$ extract of $R$. officinalis (leaves, $200 \mathrm{mg} / \mathrm{kg}$ ) showed HPP against the chronic hepatic damage (cirrhosis) caused by $\mathrm{CCl}_{4}(200 \mathrm{mg} / \mathrm{kg})$ in Sprague Dawley rats. The extract administered by i.g. route over 12 weeks in two treatment assays: in one, $\mathrm{CCl}_{4}$ was co-administer with extract, and in the other model, extract was administer once the hepatic damage (cirrhosis) was established. After the treatment period, they extracted the liver and determined levels of ALT, glucogen, Lpx and gama-glutamyltranspeptidase ( $\gamma$-GTP) and performed histological analysis. The $\mathrm{CCl}_{4}$ increased levels of ALT, glucogen, Lpx and $\gamma$-GTP; however, the group that received the extract reduced cirrhosis and fibrosis, as well as levels of the biochemical parameters, in both models. The authors concluded that the HPP effect of the $\mathrm{MeOH}$ extract of $R$. officinalis was due to its antioxidant or free radical scavenger activity. ${ }^{36}$ Other authors have been reported that the EtOH extract $(80 \%)$ of $R$. officinalis $(20 \mathrm{mg} / \mathrm{kg})$ administered by i.g. route over 30 days reduced levels of Lpx, ALT, AST and ALP in rabbits with hepato-renal damaged induced with $\mathrm{Pb}\left(\mathrm{C}_{2} \mathrm{H}_{3} \mathrm{O}_{2}\right)_{2}$. In addition, levels of SOD and CAT were slightly higher in this group than the group with $\mathrm{Pb}\left(\mathrm{C}_{2} \mathrm{H}_{3} \mathrm{O}_{2}\right)_{2}$, without reaching the levels of the control group. At 
the histological level, they observed that the $\mathrm{MeOH}$ extract induced the regeneration of hepatocytes. ${ }^{18}$ On the other hand, the $\mathrm{H}_{2} \mathrm{O}$ extract of $R$. officinalis $(10 \mathrm{~mL} / \mathrm{kg})$ administered by i.g. route showed a HPP effect against the damage induced with coal tar creosote in male Wistar rats. Creosate $(50 \mathrm{mg} / \mathrm{mL}$, solubilized in olive oil) was administer during the first three days of treatment. The results indicated that Lpx, GSH, GOx, SOD, CAT, AST, ALT, AST, and ALP levels in liver were very similar between the group that received the extract and the healthy group. These values were lower in the group that received creosote. In addition, the extract lowered levels of Lpx and normalized the activity of GOx, SOD, CAT and GST while increasing the content of GSH. ${ }^{37}$ Likewise, the $\mathrm{H}_{2} \mathrm{O}$ extract of $R$. officinalis $(220 \mathrm{mg} / 10 \mathrm{~mL})$ showed poor HPP effect in male Wistar rats with hepatic damage induced with azathioprine, which induced oxidative stress and increased the level of Lpx. The extract slightly reduced levels of Lpx, AST and ALT, and stimulated the activity of SOD, CAT and GPS. ${ }^{14}$ According to our results, the EMRO extract $(250 \mathrm{mg} / \mathrm{kg})$ administered during 91 days (chronic period) showed protection against the damage caused by the mixture of three basic drugs used to treat TB (INH:RIF:PZA), by reducing levels of AST and ALT compared to the group that received antiTB, without reaching the levels shown by the control group (vehicle). It is important to point out that the levels of these enzymes were similar to those shown by SIL (positive hepatoprotection control). In addition, the administration of the EMRO extract increased levels of CAT and GPx compared with group II (antiTB). In previous studies, it has been demonstrated that the polar extracts $\left(\mathrm{H}_{2} \mathrm{O}, \mathrm{MeOH}\right.$ or EtOH) from $R$. officinalis showed HPP effect against the damage caused by various hepatotoxic agents, such as $\mathrm{CCl}_{4}$, coal tar creosote, azathioprine or $\mathrm{Pb}\left(\mathrm{C}_{2} \mathrm{H}_{3} \mathrm{O}_{2}\right)_{2}$. However, to date the HPP effect of $R$. officinalis against the damage caused by the mixture of antiTB drugs (RIF:INH:PZA) have not been reported. These antiTB drugs are used in the treatment of TB (sensitive, MDR or XDR cases) for long periods. ${ }^{19,20,32-35}$ The HPP effect found for the EMRO extract is due to the presence of antioxidant and anti-inflammatory compounds that have been described in R. officinalis, such as rosmarinic acid and carnosol, among others. ${ }^{5,8,13,16-18,36}$ It should be pointed out that during the experimentation process none of the animals died. Histological analysis indicates that livers of the study animals (groups I-IV) did not present significant alterations during the treatment period (91 days). However, in histological slices of the kidney, it was observed that group II (antiTB) showed severe inflammatory lymphoid infiltrate, and in groups III (antiTB/SIL) and IV (antiTB/EMRO) this damage was moderate and scant, respectively.

In addition, the antiTB drugs (INH:RIF:PZA) administered over a period of 91 days provoked more damage to the kidney than the liver. In this study, the levels of urea and creatinine in group II (anti-TB group) increased, on the contrary in groups III and IV, which received the extract and SIL, these values decreased. To date, the nephroprotector effect of EMRO in rats or mice has not been reported, only the nephroprotector effect of the $R$. officinalis EtOH extract, administered for 30 days by i.g. route in rabbits with renal damage caused by lead acetate $(30 \mathrm{mg} /$ kg). ${ }^{18}$ In that paper, the authors reported that this extract at $30 \mathrm{mg} / \mathrm{kg}$ (administered during 30 days); reduced levels of urea and creatinine, while group I (with hepatic damage induced with lead acetate, $30 \mathrm{mg}$ / $\mathrm{kg}$ ) showed elevated levels. Histologically, they reported that the lead acetate caused severe congestion and hemorrhage in the peritubular capillaries, interstitial nephritis, fibrosis and lymphocytic infiltration. These alterations were reduced in the group that received the EtOH extract, where only scant degenerative changes of the vacuoles were observe in some tubules. To date, there are few works that report the nephroprotector effect of medicinal plant extracts against the damage caused by antiTB drugs (RIF:INH:PZA). Hussein et al., ${ }^{23}$ described that the EtOH extract $(80 \%)$ of Ruta graveolens protects the kidney (study in rats) against the damage caused by the mixture INH:RIF (50:50 mg/ $\mathrm{kg}$ ), when it was administered over 45 days. The extract reduced the levels of urea, creatinine, uric acid, TNF- $\alpha$, Lpx, and stimulated the activity of GPx, SOD and GSH. Histologically, it was noted that the kidney damage was less than that generated by the INH:RIF mixture. These results contribute to the exploration of the potential benefit of $R$. officinalis against the damage caused by antiTB drugs, which are basic to the TB treatment and cannot be substituted by other drugs.

\section{CONCLUSIONS}

The $\mathrm{MeOH}$ extract of Rosmarinus officinalis $(250 \mathrm{mg} / \mathrm{kg}$ ) administered by i.g. route during a period of 91 days favored body weight gain. Also, lowered levels of hepatic enzymes (AST and ALT), oxidated proteins, and increased levels of GPx and CAT; it also reduced the levels of urea and creatinine respect to the group that received the antiTB drug mixture (RIF:INH:PZA), but without reaching the levels of the control group. In liver, histologically, no significant damage was observed; however, the kidneys of the group that received the mixture of RIF:INH:PZA showed severe inflammatory infiltrate, effect that was reduced in the group that received the extract. $R$. officinalis is a potential nephroprotective agent against kidney damage caused by antiTB.

\section{ACKNOWLEDGMENTS}

\section{Funding}

This work was developed with the financing of the Fondo de Investigación en Salud project FIS/IMSS/PROT/G16/1577 (CLIC: R-2015-3601-47).

\section{Author contributions}

JIMA supervised, designed and wrote the manuscript, SRGA and CGJ carried out the experimental work and analysed the results.

\section{Conflicts of interest}

All the authors declare that they have no conflict of interest in this work.

\section{REFERENCES}

1. Andrade JM, Faustino C, Garcia C, Ladeiras D, Reis CP, Rijo P. Rosmarinus officinalis $L .:$ an update review of its phytochemistry and biological activity. Future Sci OA. 2018;4:FSO283. https://doi. org/10.4155/fsoa-2017-0124

2. Begum A, Sandhya S, Shaffath-Ali S, Vinod KR., Reddy S, Banji D. An in-depth review on the medicinal flora Rosmarinus officinalis (Lamiaceae). Acta Sci Pol Technol Aliment. 2013;12:61-73

3. Soria-Fregozo C, Miranda Beltrán ML, Flores Soto ME, Pérez Vega $\mathrm{MI}$, Rodríguez Rodríguez RY, López Velázquez $A L$, et al. Protective effect of Rosmarinus officinalis L. on the expression of the glutamate transporter (GLT-1) and neuronal damage in the frontal cortex of $\mathrm{CCl}_{4}$ induced hepatic damage. J Med Plants Res. 2012;6:5886-5894

4. Alfonso MS, de O Silva AM, Carvalho EB, Rivelli DP, Barros Sb, Rogero MM, et al. Phenolic compounds from Rosemary (Rosmarinus officinalis L.) attenuate oxidative stress and reduce blood cholesterol concentrations in diet-induced hypercholesterolemic rats. Nutr Metab (Lond). 2013;10:19. https://doi.org/ 10.1186/1743-7075-10-19

5. de Oliveira JR, Camargo SEA, de Oliveira LD. Rosmarinus officinalis $\mathrm{L}$. (rosemary) as therapeutic and prophylactic agent. J Biomed Sci. 2019;26:5-27. https://doi.org/10.1186/s12929-019-0499-8

6. Harach T, Aprikian O, Monnard I, Moulin J, Membrez M, Béolor C, et al. Rosemary (Rosmarinus officinalis L.) leaf extract limits weight gain and liver steatosis in mice fed a high-fat diet. Planta Med. 2010;76:566-571. https://doi.org/10.1055/s-0029-1240612

7. Romo-Vaquero M, Larrosa M, Yáñez-Gascón MJ, Issaly N, Flanagan $\mathrm{J}$, Roller $\mathrm{M}$, et al. A Rosemary extract enriched in carnosic acid improves circulating adipocytokines and modulates key metabolic sensors in lean Zucker rats: Critical and contrasting differences in the obese genotype. Mol Nutr Food Res. 2014;58:942-953. https://doi. org/10.1002/mnfr.201300524 
8. Altinier G, Sosa S, Aquino RP, Mencherini T, Loggia RD, Tubaro A. Characterization of topical antiinflammatory compounds in Rosmarinus officinalis L. J Agric Food Chem. 2007;55:1718-1723 https://doi.org/10.1021/jf062610

9. Colica C, Di Renzo L, Aiello V, De Lorenzo A, Abenavoli L. Rosmarinic acid as a potential antiinflammatory agent. Rev Recent Clin Trials. 2018;13:240-242. doi: 10.2174/157488711304180911095818

10. González-Vallinas M, Reglero G, Ramírez de Molina A. Rosemary (Rosmarinus officinalis L.) extract as a potential complementary agent in anticancer therapy. Nutr Cancer. 2015;67:1221-1229.https:// doi.org/10.1080/01635581.2015.1082110

11. Ngo SN, Williams DB, Head RJ. Rosemary and cancer prevention: preclinical perspectives. Crit Rev Food Sci Nutr. 2011;51:946-954. https://doi.org/10.1080/10408398.2010.490883

12. Peng $\mathrm{CH}$, Su JD, Chyau CC, Sung TY, Ho SS, Peng CC, et al. Supercritical fluid extracts of Rosemary leaves exhibit potent antiinflammation and anti-tumor effects. Biosci Biotechnol Biochem. 2007;71:2223-2232. https://doi.org/10.1271/bbb.70199

13. Rocha J, Eduardo-Figueira M, Barateiro A, Fernandes A, Brites D, Bronze R, et al. Anti-inflammatory effect of Rosmarinic Acid and an extract of Rosmarinus officinalis in rat models of local and systemic inflammation. Basic Clin Pharmacol Toxicol. 2014;116:398-413. https:// doi.org/10.1111/bcpt.12335

14. Amin A, Hamza AA. Hepatoprotective effects of Hibiscus, Rosmarinus and Salvia on azathioprine-inducted toxicity in rats. Life Sci. 2005;77:266-278. https://doi.org/10.1016/j.lfs.2004.09.048

15. Ramadan KS, Khalil OA, Danial EN, Alnahdi HS, Ayas NO. Hypoglycemic and hepatoprotective activity of Rosmarinus officinalis extract in diabetic rats. J Physiol Biochem. 2013;69:779-783. https:// doi.org/10.1007/s13105-013-02538

16. Sotelo-Félix JI, Martínez-Fong D, Muriel De la Torre P. Protective effect of carnosol on $\mathrm{CCl}_{4}$-induced acute liver damage in rats. Eur $\mathrm{J}$ Gastroenterol Hepatol. 2002;14:1001-1006

17. Sotelo-Félix JI, Martínez-Fong $D$, Muriel P, Santillán RL, Castillo $D$, Yahuaca P. Evaluation of the effectiveness of Rosmarinus officinalis (Lamiaceae) in the alleviation of carbon tetrachloride-induced acute hepatotoxicity in the rat. J Ethnopharmacol. 2002;81:145-154. https:// doi.org/10.1016/S03788741(02)00090-9

18. Mohamed WA, Abd-Elhakim YM, Farouk SM. Protective effects of ethanolic extract of rosemary against lead-induced hepato-renal damage in rabbits. Exp Toxicol Pathol. 2016;68:451-461. https://doi. org/10.1016/j.etp.2016.07.003

19. Günther G. Multidrug-resistant and extensively drug-resistant tuberculosis: A review of current concepts and future challenges. Clin Med (Lond). 2014;14: 279-285. https://doi.org/10.7861/ clinmedicine. 14-3-279

20. Jiménez-Arellanes MA, Franco-García ML, Léon-Díaz R. Current status of Mexican medicinal plants as source of antimycobacterial and antituberculosis compounds. J Infect Dis Ther. 2019;7:1000414:14. https://www.omicsonline.org/open-access/current-status-frommexican-medicinal-plants-as-source-of-antimycobacterial-andantituberculosis-compounds.pdf

21. Njoku DB. Drug-induced hepatotoxicity: Metabolic, genetic and immunological basis. Int J Mol Sci. 2014;15:6990-7003. https://doi. org/10.3390/ijms15046990

22. World Health Organization (WHO). Global tuberculosis report 2018 , https://www.who.int/tb/publications/global_report/en/ (consultado julio 2020).

23. Hussein OE, Germoush MO, Mahmoud AM. Ruta graveolens Protects Against Isoniazid/Rifampicin-Induced Nephrotoxicity through Modulation of Oxidative Stress and Inflammation. Glob J Biotechnol Biomater Sci. 2016;1:017-022
24. Mahmoud AM, Ahmed RR, Soliman HA, Salah M. Ruta graveolens and its active constituent rutin protect against diethylnitrosamineinduced nephrotoxicity through modulation of oxidative stress. J Appl Pharm Sci. 2015;5:16-21. DOI: 10.7324/JAPS.2015.501004

25. NOM-062-ZOO-1999. Norma Oficial Mexicana NO. Especificaciones técnicas para la producción, 351 cuidados y uso de los animales de laboratorio. México. http://www.fmvz.unam.mx/fmvz/principal/ archivos/062ZOO.PDF

26. Pérez-González MZ, Siordia-Reyes AG, Damián-Nava P, HernándezOrtega S, Macías-Rubalcava ML, Jiménez-Arellanes MA. Hepatoprotective and Anti-Inflammatory Activities of the Cnidoscolus chayamansa (Mc Vaugh) Leaf Extract in Chronic Models, Evid Based Complement Altern Med 2018;2018:1-12. doi:10.1155/2018/3896517.

27. Pérez-González MZ, Macías-Rubalcava ML, Hernández-Ortega $S$, Siordia-Reyes G. Jiménez-Arellanes MA. Additional compounds and the therapeutic potential of Cnidoscolus chayamansa (McVaugh) against hepatotoxicity induced by antitubercular drugs. Biomed Pharmacother. 2019;117:109140. https://doi.org/10.1016/j. biopha.2019.109140

28. Beltrán-Villalobos KL, Déciga-Campos $M$, Aguilar-Mariscal $H$, González-Trujano M. E, Martínez-Salazar MF, Ramírez-Cisneros A, et al. Synergistic antinociceptive interaction of Syzygium aromaticum or Rosmarinus officinalis coadministered with ketorolac in rats. Biomed Pharmacother. 2017;94:858-864. https://doi.org/10.1016/j. biopha.2017.07.166

29. Lukaczer D, Darland G, Tripp M, Liska DA, Lerman RH, Schiltz B, et al. A Pilot trial evaluating meta050, a proprietary combination of reduced iso-alpha acids, rosemary extract and oleanolic acid in patients with arthritis and fibromyalgia. Phytother Res. 2005;19:864-869. https:// doi.org/10.1002/ptr.17

30. Martínez AL, González-Trujano ME, Chávez M, Pellicer F. Antinociceptive effectiveness of triterpenes from rosemary in visceral nociception. J Ethnopharmacol. 2021;142:28-34. https://doi. org/10.1016/j.jep.2012.03.052

31. Ramírez-Marroquín OA, Jiménez-Arellanes MA. Hepato-protective effect from natural compounds, biological products and medicinal plant extracts on antitubercular drug-induced liver injuries: A systematic review. Med Aromat Plants. 2019;8:1-12.

32. Jiménez-Arellanes MA, Gutiérrez-Rebolledo GA, Meckes-Fischer $M$, León-Díaz R. Medical plant extracts and natural compounds with a hepatoprotective effect against damage caused by antitubercular drugs: A review. Asian Pac J Trop Med. 2016;9:1141-1149. https://doi. org/10.1016/j.apjtm.2016.10.010

33. Ramappa V, Aithal GP. Hepatotoxicity related to anti-tuberculosis drugs: Mechanisms and management. J Clin Exp Hepatol. 2013;3:3749. https://doi.org/10.1016/j.jceh.2012.12.001

34. Eminzade S, Uraz F, Izzettin FV. Silymarin protects liver against toxic effects of anti-tuberculosis drugs in experimental animals. Nutr Metab (Lond). 2008;5:1-8.

35. Rodríguez-Flores EM, Mata-Espinosa D, Barrios-Payan J, MarquinaCastillo B, Castañón Arreola M, Hernández-Pando R. A significant therapeutic effect of silymarin administered alone, or in combination with chemotherapy, in experimental pulmonary tuberculosis caused by drug-sensitive or drug-resistant strains: In vitro and in vivo studies. PLoS ONE. 2019;14:e0217457. https://doi.org/10.1371/journal. pone. 0217457

36. Gutiérrez R, Alvarado JL, Presno M, Pérez-Veyna O, Serrano CJ, Yahuaca P. Oxidative stress modulation by Rosmarinus officinalis in $\mathrm{CCl}_{4}$-induced liver cirrhosis. Phytother Res. 2010;24:595-601. https:// doi.org/10.1002/ptr.2997

37. El-Demerdash FM, Abbady EA, Baghdadi HH. Oxidative stress modulation by Rosmarinus officinalis in creosote-induce hepatotoxicity. Environ Toxicol. 2014;1:85-92. https://doi.org/10.1002/ tox.22024 


\section{GRAPHICAL ABSTRACT}

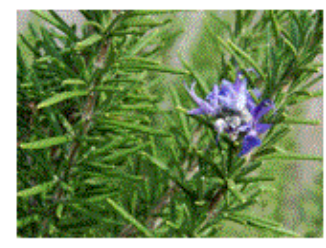

Rosmarinus officinalis (Lamiaceae family)

Aerial parts

EMRO (Methanolic extract contain

rosmarinic acid, carnosol, UA/OA)

|

Male Balb/C mice $(24 \pm 2 \mathrm{~g})$

treated during 91 days by i.g. route

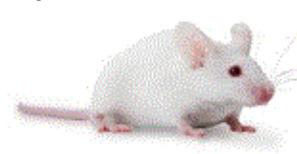

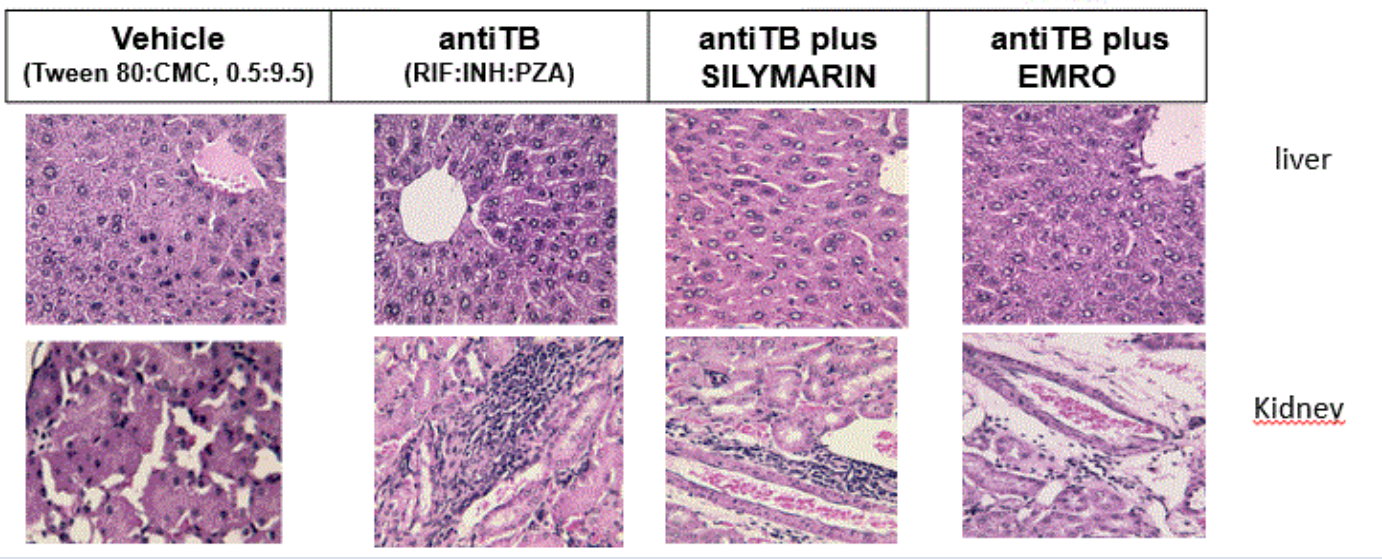

\section{ABOUT AUTHORS}

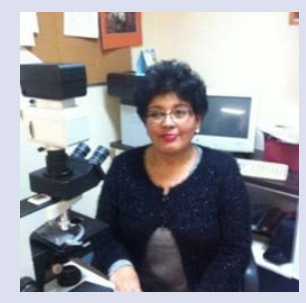

M. Sc. ALICIA GEORGINA SIORDIA REYES

CHIEF OF PEDIATRIC PATHOLOGY DEPARTMENT FROM HOSPITAL DE PEDIATRIA CMN SXXI, IMSS

PROFESSOR OFTHE SUBSPECIALITY IN OF PEDIATRIC PATHOLOGY, UNAM

MEMBER OF NATIONAL RESEARCH SYSTEM (I)

MEMBER OF THE NATIONAL ACADEMY OF PEDIATRICS

georginasiordia@hotmail.com

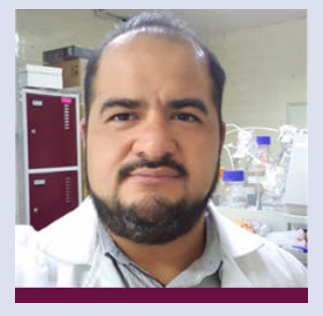

Dr. Sc. Jorge Cornejo-Garrido is a professor titular at the National School of Medicine and Homeopathy of the National Polytechnic Institute. His research focuses on the evaluation of the safety and efficacy of natural compounds and extracts with potential for the treatment of chronic degenerative diseases. Member of national research system (I) jcornejog@ipn.mx

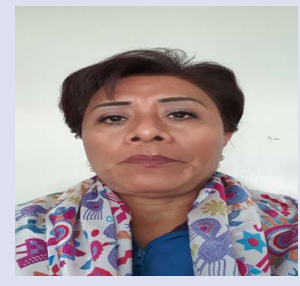

Maria Adelina Jiménez Arellanes, I am a senior researcher at the Medical Research Unit in Pharmacology of the Hospital de Especialidades CMN Siglo XXI, IMSS. My main line of research is to explore the hepatoprotective and antitubercular potential of medicinal plants, their acute and subacute toxicity. And obtain and identifying of the bio-active compounds from medicinal plants Member of national research system (nivel II) adelinajim08@prodigy.net.mx

Cite this article: Siordia-Reyes GA, Cornejo-Garrido J, Jiménez-Arellanes MA. Nephro- and hepatoprotective effect of Rosmarinus officinalis against damage induced with antiTB drugs using a chronic model. Pharmacog J. 2021;13(3): 722-9. 